\title{
Radiotherapy as an only saving option for oncologic patient in hemorrhagic shock
}

\section{Denis Pizhin $^{1,2}$, João Teles Carvalho'}

1 - Centro Hospitalar Universitário de Lisboa Central, Hospital São José, Lisboa, Portugal

2 - Centro Hospitalar São Bernardo, Setúbal, Portugal

\section{PURPOSE OF THE STUDY: Massive upper} gastrointestinal bleeding is a life-threatening emergency. Hematological malignancies are very rare causes of this type of bleeding. In this case, we present a gastric diffuse large Bcell lymphoma (DLBCL) with a massive upper gastrointestinal system bleeding, causing shock and an only option of radiotherapy at this emergency setting.

MATERIALS AND METHODS: A 52-year-old male patient was admitted to emergency department with hematemesis and hematochezia. In physical examination patient was confused, pale and sweaty; his vital signs were unstable with a heart rate of 150 per minute and a blood pressure of $60 / 30 \mathrm{mmHg}$. His hemoglobin $(\mathrm{Hb})$ level was found $\mathbf{4 . 7 1} \mathrm{g} / \mathrm{dL}$.

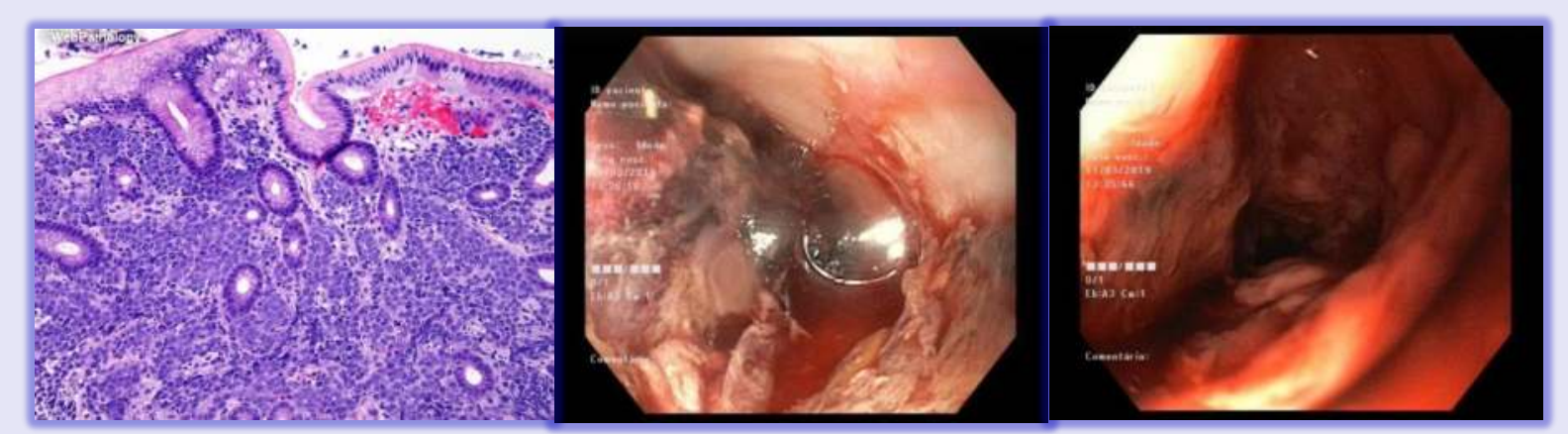

Pic.1 Histology and endoscopy of gastric diffuse large B-cell lymphoma
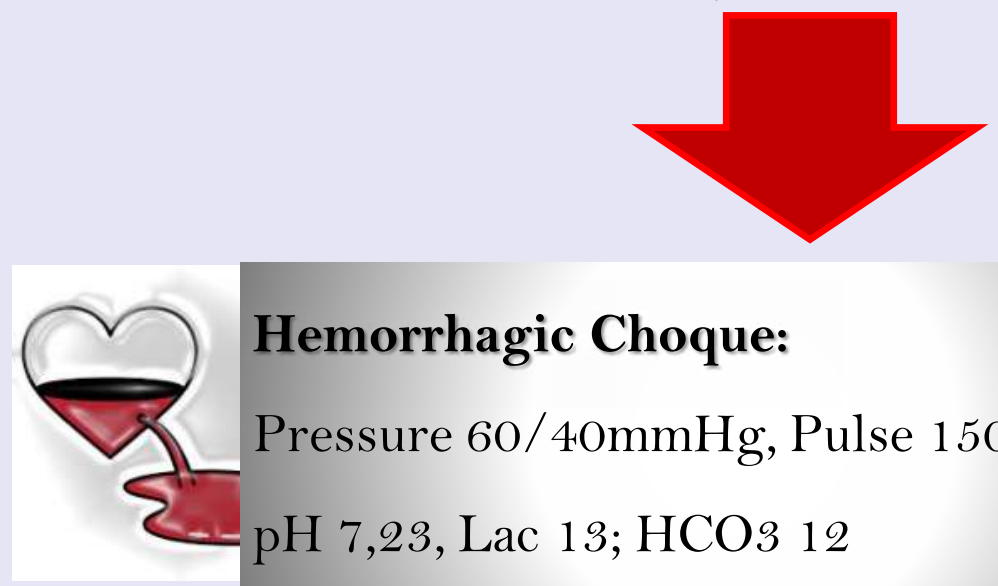

Hemorrhagic Choque:

Pressure 60/40mmHg, Pulse 150, Hb 4,8; pH 7,23, Lac 13; HCO3 12
RESULTS: A resuscitation measures were started, first ABG showed severe compensated metabolic acidosis ( $\mathrm{pH}$ : 7,420; pCO2: 9,0 mmHg; pO2: 190,0 mmHg, HCO3: 5,8, Lac >15,0 $\mathrm{mmol} / \mathrm{L})$. He was intubated and ventilated. After adequate volume expansion (crystalloids and blood products), a noradrenalin was started. An attempt of upper gastric endoscopy was unsuccessful as a tumor occupied all gastric lumen, and there was no surgical solution due to extension of tumor lesions. A desperate option was proposed - radiotherapy session. Two hours after he performed a three dimensional (3D) conformational radiotherapy with a total dose of $8 \mathrm{~Gy}$. Immediately after, a patient became responsive to blood transfusion and hemodynamic parameters started to improve. A noradrenalin was stopped $12 \mathrm{~h}$ after ICU admission. A chemotherapy (Cyclophosphamide, Doxorubicin, Vincristine and Prednisone) was started next day. A patient was extubated at day 5 and discharged from ICU to the oncologic ward at day 7. One month later he was discharged from hospital.
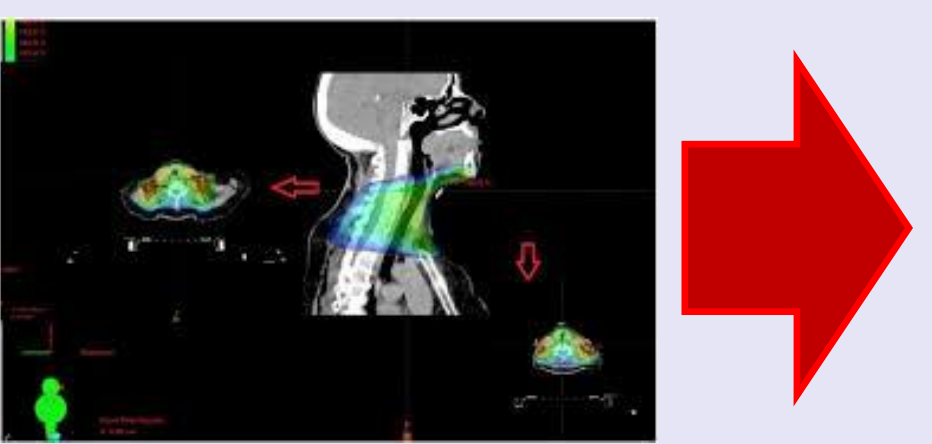

ICU admission

Oncologic ward Home

Pic. 2

$3 \mathrm{D}$ conformational radiotherapy

CONCLUSIONS: Although not listed as a common cause of massive gastrointestinal bleeding DLBCL can cause life-threatening situations mostly because of its malignant nature. However, in most cases a bleeding cancer responses to radiotherapy is not immediate, but in some desperate cases, an external beam radiation therapy might stop bleeding and save lives, when applied in emergency setting.

\footnotetext{
Pereira J, Mancini I, Bruera E. The management of bleeding in patients with advanced cancer. In: Portenoy RK, Bruera E, eds. Topics in Palliative Care, Volume 4. New York: Oxford University Press, 2000:163-183

Yavorski R. T., Wong R. K. H., Maydonovitch C., Battin L. S., Furnia A., Amundson D. E. Analysis of 3,294 cases of upper gastrointestinal bleeding in military medical facilities. American Journal of Gastroenterology. 1995; 90(4):568-573.

Jutabha R. Jensen DM (1996) Management of upper gastrointestinal bleeding in the patient with chronic liver disease. Med Clin North Am 80 (5): 1035-1068

Rockall T. A., Logan R. F. A., Devlin H. B., Northfield T. C. Incidence of and mortality from acute upper gastrointestinal hemorrhage in the United Kingdom. British Medical Journal. 1995; 311 (6999):222226. doi: 10.1136/bmj.311.6999.222

Friedberg J. W., Fisher R. I. Diffuse large B-cell lymphoma. Hematology/Oncology Clinics of North America. 2008;22(5):941-952 doi: 10.1016/j.hoc.2008.07.002.

Ferreri A. J. M., Montalbán C. Primary diffuse large B-cell lymphoma of the stomach. Critical Reviews in Oncology/Hematology. 2007;63 (1):65-71. doi: 10.1016/j.critrevonc.2007.01.003

Wang Y. G., Zhao L. Y., Liu C. Q., et al. Clinical characteristics and prognostic factors of primary gastric lymphoma: a retrospective study with 165 cases. Medicine. 2016;95(31)

Avilés A., Nambo M. J., Neri N., et al. The role of surgery in primary gastric lymphoma: results of a controlled clinical trial. Annals of Surgery. 2004:240 (1):44-50. doi: 10.1097/01.sla.0000129354.31318.f1

Meguro A., Ozaki K., Sato K., et al. Rituximab plus 70\% cyclophosphamide, doxorubicin, vincristine and prednisone for Japanese patients with diffuse large B-cell lymphoma aged 70 years and older. Leukemia and Lymphoma. 2012;53(1):43-49. doi: 10.3109/10428194.2011.600486.

10. Shum J. B., Jayaraman S., Croome K., Quan D. Upper gastrointestinal and intra-abdominal hemorrhage secondary to diffuse large B-cell gastric lymphoma. Canadian Journal of Surgery. 2008;51(3):E56-E57

1. Stratigos P., Kouskos E., Kouroglou M., et al. Emergency pancreatoduodenectomy (Whipple procedure) for massive upper gastrointestinal bleeding caused by a diffuse B-cell lymphoma of the duodenum:

report of a case. Surgery Today. 2007;37 (8):680-684. doi: 10.1007/s00595-007-3465-0. 